\title{
Liderança no Judiciário: o reconhecimento de magistrados como líderes
}

\author{
Luciano José Martins Vieira \\ Universidade Federal do Rio Grande do Sul \\ Silvia Generali da Costa \\ Universidade Federal do Rio Grande do Sul
}

\begin{abstract}
Considerando as pressões sociais nos últimos anos por mudanças no Poder Judiciário, o estudo tem como objetivo identificar o que faz com que um magistrado da Justiça Estadual do Rio Grande do Sul seja reconhecido como um líder pelos seus pares. Para tanto descreve as funções da liderança e tece considerações sobre a liderança no setor público. Foram realizadas entrevistas individuais semiestruturadas com 12 magistrados e na análise dos dados foi utilizada a técnica da análise de conteúdo. Verificou-se que tal reconhecimento decorre da eleição e escolha para ocupar cargos importantes; do conhecimento jurídico; da capacidade de gestão; e das habilidades de mobilização e de interação. A liderança exercida encontra barreiras na estrutura organizacional; nas dificuldades de diálogo e de cooperação entre magistrados; e na falta de uma formação específica em liderança e gestão.
\end{abstract}

Palavras-chave: liderança; setor público; reconhecimento de líderes; Poder Judiciário.

Liderazgo en el Poder Judicial: el reconocimiento de magistrados como líderes

Considerando las presiones sociales en los últimos años por los cambios en el Poder Judicial, el estudio tiene como objetivo identificar lo que hace que un magistrado de la Corte del Estado de Rio Grande do Sul ser reconocido como un líder por sus pares. Por tanto se describen las funciones de liderazgo y reflexiona sobre el liderazgo en el sector público. Se llevaron a cabo entrevistas individuales semiestructuradas con 12 jueces y análisis de datos fue a través de la técnica de análisis de contenido. Se encontró que el reconocimiento es resultado de las elecciones y elegir a ocupar puestos importantes, el conocimiento legal, la capacidad de gestión y las habilidades de movilización y de interacción. El liderazgo ejercido encontrarse con obstáculos en la estructura organizacional, la dificultad del diálogo y de cooperación entre los magistrados, y la falta de formación específica en liderazgo y gestión.

Palabras clave: liderazgo; sector público; reconocimiento de líderes; Poder Judicial.

Artigo recebido em 23 jul. 2012 e aceito em 16 abr. 2013. 
Leadership in the Judiciary: the recognition of magistrates as leaders

Considering the social pressures in recent years by changes in the Judiciary, the study aims to identify what makes a magistrate of the State Justice of Rio Grande do Sul is recognized as a leader by their peers. For both describes the functions of leadership and reflects on the leadership in the public sector. Were performed semi-structured interviews with 12 magistrates and the data analysis was through the content analysis technique. It was found that the recognition result from the election and choice to occupy important posts, the legal knowledge, the management capacity and interaction and mobilization skills. The practiced leadership finds barriers in the organizational structure, the difficulty of dialog and of cooperation between magistrates, and the lack of a specific training in leadership and management.

KEYwords: leadership; public sector; leader recognition; Judiciary.

\section{Introdução}

O Poder Judiciário brasileiro nos últimos anos tem sofrido grande pressão social por mudanças em razão da denominada "crise do Judiciário", que "diz respeito a uma estrutura pesada, sem agilidade, incapaz de fornecer soluções em tempo razoável, previsíveis e a custos acessíveis para todos" (Sadek, 2004:88). Uma das causas diagnosticadas é a carência em aspectos relacionados à gestão, que inclui o número insuficiente de recursos humanos; a falta de planejamento; a falta de formação gerencial de magistrados e servidores; e a deficiência no controle administrativo (Costa, Martinewski e Vieira, 2006).

De modo a minimizar alguns dos problemas relacionados à gestão, foi criado, a partir da Emenda Constitucional no 45/2004, o Conselho Nacional de Justiça (CNJ) com as seguintes atribuições: zelar pela autonomia do Judiciário; exercer o controle da atuação administrativa e financeira dos órgãos do poder; fiscalizar o cumprimento dos deveres funcionais de magistrados e servidores; e realizar o planejamento e a publicidade de dados sobre o Judiciário. Desde 2005 o órgão expediu dezenas de normatizações, de cumprimento obrigatório pelos órgãos, magistrados e servidores da Justiça, que abordaram as funções administrativas do planejamento, da organização e do controle (Vieira e Pinheiro, 2008).

Porém, a existência de normas não significa que novas orientações e práticas no âmbito gerencial serão aplicadas automaticamente a partir da sua promulgação. O engajamento dos participantes de uma organização é condição sine qua non para que mudanças importantes sejam implementadas. E aí reside a importância da figura do líder (ou líderes), como alguém que planeja e viabiliza mudanças por meio de sua influência sobre os demais membros da organização.

O Poder Judiciário é uma instituição pública que possui uma singularidade que é a grande autonomia que o magistrado possui dentro da estrutura da organização. $\mathrm{O}$ magistrado é um tipo peculiar de servidor público, pois o texto constitucional no art. 92 determina que ele é um órgão do Judiciário e em razão disso possui garantias específicas como a vitaliciedade, inamovibilidade e irredutibilidade de vencimentos (Brasil, 1988). Ele não está subordinado 
hierarquicamente a nenhum outro juiz quando da interpretação e da aplicação da lei, e somente juízes podem ocupar os cargos diretivos máximos da instituição, como a direção de fóruns, a presidência dos tribunais, a função de corregedores e como membros de conselhos deliberativos ou consultivos. Também ao magistrado compete supervisionar as atividades administrativas realizadas pelos servidores na unidade jurisdicional em que atua.

Mas o Judiciário apresenta historicamente grande resistência a mudanças no âmbito administrativo (Jobim, 2005; Nalini, 2006; Vieira, 2009). Para que seja possível minimizar algumas das causas e das consequências da crise referida no que tange à administração judiciária, é preciso que alguns desses importantes atores organizacionais sejam reconhecidos como lideranças que viabilizem mudanças consistentes de modo a evitar o pleito recorrente de contratação de mais magistrados e servidores, o que seria, segundo Jobim (2005), uma solução paliativa para os problemas de gestão. Em razão disso, o reconhecimento do magistrado como líder efetivo traz importantes implicações para a instituição, dado que líderes percebidos como competentes têm mais possibilidades de realizar mudanças (Yukl, 2010).

A partir do exposto, o estudo tem como objetivo principal identificar o que faz com que um magistrado da Justiça Estadual do Rio Grande do Sul seja reconhecido como um líder pelos seus pares. O Judiciário gaúcho é o quarto maior Poder Judiciário estadual, se considerado o número de magistrados e servidores (Conselho Nacional de Justiça, 2012). Em 2010 realizou o seu planejamento estratégico para o período 2010-14, no qual indicou expressamente que a existência de líderes é necessária para que os objetivos estratégicos tornem-se realidade de modo a "atender as necessidades e expectativas de uma sociedade em evolução e cada vez mais exigente" (Tribunal de Justiça do Rio Grande do Sul, 2010:1).

Assim, investiga-se a liderança em um contexto pouco pesquisado no país, que é a liderança no setor público. A pesquisa de Martins e colaboradores (2010) sobre a produção acadêmica nacional em gestão de pessoas no setor público constatou que, de 174 artigos publicados no período de 2000 a 2009, somente 11 (6,32\%) versaram sobre liderança. Ademais, o presente trabalho aborda um ente estatal pouco pesquisado na área de administração pública no país, o Poder Judiciário, conforme Akutsu e Guimarães (2012) e Nogueira e colaboradores (2012).

O estudo se justifica em razão de o Judiciário possuir grande importância para a viabilização da democracia, pois a ele compete o monopólio da prestação da tutela jurisdicional arbitrando conflitos e garantindo direitos, além de poder influenciar nos resultados das políticas públicas deliberadas pelos demais poderes em razão da possibilidade de alterá-las parcial ou totalmente, sustentá-las e legitimá-las, atrasar a sua implementação ou rejeitá-las (Vieira e Pinheiro, 2008). Entende-se que, dado o momento de pressão por mudanças pelo qual o Judiciário está passando, é oportuno o estudo de como os principais membros desta instituição reconhecem dentre os seus pares aqueles que são apontados na literatura como os agentes facilitadores das mudanças organizacionais e que possibilitam a coordenação de esforços para o alcance de objetivos.

Na primeira seção é feita uma descrição das funções da liderança. Na segunda seção ocorre a explanação das características da liderança exercida no setor público. Após, há a 
descrição dos procedimentos metodológicos adotados. Na quarta seção ocorre a apresentação e análise dos dados e por derradeiro são tecidas algumas conclusões.

\section{Funções da liderança}

Em que pese a liderança ser objeto de estudo há décadas, não há uma definição inconteste sobre tal fenômeno. Bass (1990:11) afirma que "existem tantas definições diferentes de liderança quanto o número de pessoas que tentam definir o conceito". Tal multiplicidade conceitual decorre dos diversos aspectos pelos quais a liderança é estudada, como as características ou comportamento dos líderes, ou ao contexto em que ela ocorre.

Yukl (2010:8) conceitua liderança como "o processo de influenciar outros para entender e concordar sobre o que precisa ser feito e como isto deve ser realizado, e o processo de facilitar a realização individual e coletiva de objetivos compartilhados". Já para Bass (1990:19-20):

Liderança é uma interação entre dois ou mais membros de um grupo que frequentemente envolve a construção e reconstrução da situação e das percepções e expectativas dos membros. Líderes são agentes de mudança — pessoas cujas ações afetam outras pessoas mais do que atos de outras pessoas os afetam. Liderança ocorre quando um membro do grupo modifica a motivação ou competências de outros membros deste grupo.

Para Bergamini (2009:9), a liderança "se configura como uma relação entre duas ou mais pessoas que supostamente exercem entre si uma ação de influência mútua", e para Limongi-França e Arellano (2002:259) "liderança é um processo social no qual se estabelecem relações de influência entre pessoas. O núcleo desse processo de interação humana é composto do líder ou líderes, seus liderados, um fato e um momento social”.

A partir destas definições, verifica-se que a liderança é uma relação social de influência intencional entre líder e liderados visando o alcance de objetivos, na qual ocorrem trocas sociais em que o líder obtém autoridade mediante seu reconhecimento e aceitação pelo liderado pois é considerado alguém que traz benefícios (não somente materiais) à organização, ao grupo ou a cada pessoa. A relação de influência é um processo que não depende somente da vontade do líder, mas é o resultado da soma desta com imagens, desejos e crenças compartilhadas pelos liderados (Davel e Machado, 2001).

Para Yukl (2010), a liderança é resultante de seis variáveis mutuamente relacionadas: a) traços do líder; b) comportamento do líder; c) poder do líder, que é determinado pelo conhecimento técnico, pela capacidade de persuasão, pela autoridade formal e controle sobre recompensas, e em razão das consequências dos sucessos e fracassos obtidos; d) critérios de sucesso, decorrentes dos objetivos a serem alcançados e dos valores de quem faz a avaliação dos resultados; e) variáveis situacionais, que são aquelas que reduzem a importância do líder ou tornam seu trabalho mais fácil (cultura organizacional; organização dos processos de tra- 
balho; estrutura da organização; contexto externo; complexidade do trabalho); e f) variáveis intervenientes, que são aquelas que interferem na performance individual, grupal e organizacional (motivação, habilidade e conhecimento da tarefa pelos seguidores; cooperação; confiança mútua; identificação coletiva pelo efeito do comportamento do líder na performance do grupo; capacidade de aprendizado coletivo; estratégias organizacionais).

A partir destas variáveis, Yukl (2010) identificou as 10 principais funções da liderança, que correspondem às ações esperadas de um líder. A primeira é ajudar os demais membros da organização na interpretação dos significados de eventos complexos, no entendimento do porquê eles são relevantes e na verificação de ameaças e oportunidades. A segunda é criar alinhamento entre prioridades, objetivos e estratégias a partir da criação de consensos sobre esses temas, especialmente sobre o que fazer e como fazê-lo.

A terceira função da liderança é construir comprometimento com o trabalho a ser realizado e proporcionar otimismo no ambiente laboral. A quarta é viabilizar a confiança mútua e a cooperação no trabalho. A quinta é fortalecer a identidade coletiva do grupo e, se possível, da organização. A sexta é organizar, coordenar e auxiliar a realização de atividades complexas. A sétima é facilitar o aprendizado coletivo.

A oitava ação esperada de um líder é ser ele capaz de obter o suporte político e os recursos necessários a partir da defesa dos interesses do grupo. A nona é desenvolver os liderados e proporcionar o empowerment; e a última é ser um exemplo de comportamento moral pelo não estímulo a atos não éticos.

Yukl (2010) expõe que tais funções podem ser desempenhadas por qualquer pessoa em uma organização, mas que os resultados serão mais relevantes se a pessoa for eleita, nomeada ou informalmente reconhecida como líder pela coletividade. Limongi-França e Arellano (2002:267-268) expõem que não existe um líder universal, pois este só mantém sua condição se "estiver atendendo às expectativas e às necessidades de seus liderados e grupos relacionados com o processo de influência em que está inserido".

\section{Liderança no setor público}

Villoria e Iglesias (2011) alertam que muito do que é escrito sobre liderança não deve ser adotado indistintamente na gestão pública, pois não considera as distinções entre os setores público e privado. Conforme Wart (2003), o tema liderança no setor público desperta interesse há alguns anos, mas com um número expressivamente inferior aos trabalhos sobre liderança no setor privado. $\mathrm{O}$ autor apresenta quatro causas para a pouca produção científica na área em nível internacional. A primeira decorre das diferenças entre estruturas, missões e culturas organizacionais, tipos de problemas e oportunidades existentes entre organizações públicas. A segunda é a convicção de que a liderança não poderia existir em intensidade considerável em razão da crença na elevada força advinda dos altos cargos decorrentes de uma forte hierarquia. A terceira é que a burocracia é guiada por poderosas forças que estão além do controle dos líderes, o que torna as suas contribuições relativamente insignificantes. Por fim, há a falta 
de foco dos poucos pesquisadores sobre o tema, que abrange de rotinas burocráticas até amplos debates sobre políticas públicas.

Estudo realizado pela Organização para a Cooperação e o Desenvolvimento Econômico (Ocde) expõe quatro motivos principais para o crescimento do interesse da atenção dispensada à liderança no setor público por governos. O primeiro motivo é a mudança do contexto global no qual os governos precisam se adaptar em razão da globalização das políticas econômicas e sociais, da descentralização crescente das políticas públicas entre os níveis federativos e do uso intensivo das tecnologias da informação (o que viabiliza a solução de demandas de modo rápido, transparente e flexível). Neste contexto em mutação surge a necessidade de uma nova liderança que: a) pense e aja coerentemente de modo local e global; b) valorize a carreira pública, de modo a atrair pessoas mais capacitadas; c) estimule a produção e o compartilhamento do conhecimento nas organizações públicas; d) viabilize a prestação de serviços públicos de qualidade a partir de adaptações das estruturas das organizações públicas (Ocde, 2002).

O segundo motivo é a compreensão de que direção e liderança são conceitos distintos. Enquanto o primeiro está relacionado a sistemas, processos e incentivos formais, o segundo está relacionado à influência informal através da mobilização via valores e visões (Ocde, 2002). Kotter (2000) igualmente expôs que a liderança e o gerenciamento são sistemas de ações distintos, mas complementares: o primeiro lida com e gera mudanças a partir do estabelecimento de uma visão de futuro e das estratégias para alcançá-las, enquanto o segundo lida com a complexidade a partir da elaboração de planos e orçamentos, organizando e fornecendo pessoal, e controlando e resolvendo problemas.

O terceiro é o reconhecimento da necessidade de se obter o engajamento dos servidores e não apenas a sua obediência à autoridade formal. O quarto e último motivo é a mudança da percepção de que a liderança era restrita aos níveis hierárquicos superiores para a percepção de ela envolver todos os níveis organizacionais.

Dados estes motivos, o estudo da Ocde indica os três papéis dos líderes no setor público. O primeiro papel é que as lideranças devem ser agentes de mudança e da reforma, dado que o grande problema dos órgãos públicos é saber como eles podem se adaptar às circunstâncias mutáveis quando as mudanças exigidas excedem o alcance dos instrumentos de ação existentes (Ocde, 2002).

Heifetz e Laurie (1997 apud Schwella, 2005) expõem seis princípios para o exercício da liderança em meio a problemas adaptativos no setor público: a) conhecer e refletir sobre os padrões sistêmicos da organização e sua dinâmica, em vez de agir de forma diretiva e pontual; b) viabilizar a descrição, definição e análise das reais ameaças enfrentadas pela organização; c) moderar a angústia resultante das pressões pelas mudanças; d) direcionar o esforço do grupo para efetivamente solucionar os problemas identificados; e) assegurar que todos os integrantes da organização engajem-se na solução dos problemas adaptativos, de modo a desenvolverem novas competências; f) apoiar as pessoas que manifestam opiniões, críticas e sugestões.

O segundo papel da liderança no setor público é realçar a capacidade e o desempenho organizacional, pois as lideranças devem ser capazes de motivar as equipes e disponibilizar os 
meios possíveis para que a missão da organização seja alcançada. O terceiro papel é integrar algumas atividades de gestão de recursos humanos, pois, a partir da identificação das competências esperadas, é interessante que haja uma orientação para o recrutamento e seleção, treinamento e desenvolvimento e gestão do desempenho (Ocde, 2002).

Hooijeberg e Choi (2001 apud Oliveira, Sant'anna e Vaz, 2010) expõem como especificidades da esfera pública que as lideranças deste setor devem alcançar inúmeros objetivos mediante diferentes racionalidades e interesses, ao contrário das lideranças no setor privado, que têm objetivos mais claros em razão de o propósito principal da atividade ser a obtenção do lucro. Também expõem a existência de uma dificuldade de mensurar o desempenho dos líderes no setor público, e tais lideranças sofrem um frequente turnover em razão do término do período de ocupação de um cargo ou decorrente de mudanças administrativas e políticas. Por fim, a existência de muitas leis, controles e regulamentações faz com que haja pouca discricionariedade dos líderes.

Bacon (1999) sugere algumas etapas para o desenvolvimento de líderes considerando as restrições impostas pelas características do setor público. A primeira é o comprometimento do topo hierárquico com o desenvolvimento de futuros líderes. A segunda é o desenvolvimento das competências de liderança por meio da diversificação de tarefas, que decorre da realização de cursos de capacitação e da viabilização da rotatividade de funções. A terceira é o desenvolvimento da autoconsciência das competências de liderança através da aplicação da avaliação de desempenho 360․ Outra etapa é a ampliação de capacidades a partir da participação em projetos especiais. A última etapa é a realização periódica de auditorias de liderança dentro da organização a partir da definição de indicadores que abrangem a mensuração das etapas antecedentes.

No tocante ao desenvolvimento de líderes, não existe um modelo universal e ideal, dado que cada setor público nacional possui valores e sistemas de gestão próprios, mas são identificadas nos países-membros da Ocde as seguintes tendências gerais: a) o desenvolvimento de estratégias abrangentes e sistemáticas; b) a vinculação da atual formação de gestores com o desenvolvimento da liderança; c) o estabelecimento de novas instituições para a formação de líderes; d) a definição de um perfil de competência para os futuros líderes; e) a identificação e seleção de líderes em potencial a partir das competências definidas; f) assegurar a formação contínua e que proporcione uma perspectiva holística do setor público (Ocde, 2002).

Entretanto, o desenvolvimento de lideranças no setor público requer alguns cuidados: a) garantir os interesses da coletividade, caso os líderes optem por perseguir seus próprios interesses, não atendendo às mudanças exigidas pela sociedade; b) considerar o contexto dos desafios e características de cada setor público quando do desenvolvimento de líderes, sob risco de ineficácia das atividades desta natureza; e c) ter a ciência de que uma estratégia bem-sucedida de liderança envolve a mudança cultural das organizações públicas, algo que é difícil de ocorrer (Ocde, 2002).

No contexto do serviço público brasileiro, Amaral (2006:559-560) entende que o líder esperado no setor público brasileiro é alguém 
(...) capaz de entender os diversos desafios que lhe são colocados: de inserir a administração pública nacional em um mundo globalizado; de lidar com a crescente complexidade de cada decisão pública; de enfrentar desigualdades; de lidar com as diferenças de gênero; de incorporar o tema da diversidade; de praticar a boa governança; de aumentar a capacidade de governo; e de contribuir para as necessárias reformas. (...) Além disso, entendemos que as lideranças no setor público precisam ser capazes de lidar tanto com problemas estruturados como com problemas complexos, para os quais é preciso ter capacidade de adaptação, de reflexão e de estímulo ao aprendizado.

Ainda no contexto nacional, estudo desenvolvido por Oliveira, Sant'Anna e Vaz (2010) apresenta os atributos de liderança requeridos do líder público brasileiro contemporâneo: a) capacidade de comunicação; b) capacidade de lidar com os liderados; c) legitimidade; d) bom senso; e) capacidade de agregação; f) disciplina; g) visão sistêmica; f) espírito de corpo. Os autores concluem que o desenvolvimento de lideranças é algo possível de ocorrer através de cursos que propiciem a conciliação entre a obtenção de conhecimento teórico e sua aplicação em situações práticas, além do desenvolvimento da capacidade de relacionamento interpessoal.

Outras conclusões dos autores são que, no setor público, as lideranças tenderiam a impor sua condição pelo cargo ocupado, não sendo consideradas a existência e a importância das lideranças informais; a existência de dificuldades de adoção de mecanismos de motivação dos liderados em razão dos planos de carreiras e das regras predefinidas de remuneração; e que as competências demandadas dos líderes na área pública estão mais vinculadas às habilidades e às atitudes em relação aos demais membros da organização, e que a exigência por conhecimentos técnicos recai sobre o gestor formalmente designado (Oliveira, Sant'anna e Vaz, 2010).

\section{Procedimentos metodológicos}

Adotou-se no estudo a abordagem qualitativa, dado que esta proporciona a compreensão das percepções dos pesquisados. Grande parte dos estudos sobre liderança é quantitativa, mas a pesquisa qualitativa na área é considerada adequada para a expansão da compreensão sobre o tema:

A pesquisa qualitativa traz para o estudo da liderança uma abordagem que vê a liderança pelos olhos dos líderes e dos seguidores. Neste processo, a própria noção de liderança é problematizada, ao se apresentar a variedade de significados associados à "liderança" ou "boa liderança" entre líderes e seguidores (Parry e Bryman, 2006:462-463).

A estratégia de pesquisa selecionada para atingir os objetivos foi o estudo qualitativo básico ou genérico, que, conforme Godoy (2005:86), é uma modalidade de pesquisa que contém "as características essenciais da metodologia qualitativa, mas que não possuem to- 
dos os requisitos que possibilitariam o seu enquadramento como um estudo de caso, estudo etnográfico, etnometodologia, grounded theory, ou qualquer outra modalidade específica". Para Merriam (1998), estudos dessa natureza objetivam descrever, interpretar e entender um fenômeno, um processo ou as perspectivas e as visões de mundo das pessoas envolvidas. Ou seja, há o interesse do pesquisador em compreender os significados que os participantes atribuem ao fenômeno estudado a partir de realização de entrevistas, observações ou análise de documentos.

Para a realização da coleta de dados para a pesquisa selecionou-se como fonte de evidências a realização de entrevistas individuais semiestruturadas. Foram entrevistados 12 magistrados e magistradas com atuação em todas as instâncias (primeiro e segundo graus de jurisdição) e entrâncias (inicial, intermediária e final) da justiça gaúcha, conforme identificação no quadro 1. Uma vez que o grupo de magistrados no estado do Rio Grande do Sul é restrito, 774 magistrados, com o objetivo de preservar o anonimato dos participantes não são expostos elementos que possibilitem a identificação dos respondentes, como identificação precisa do tempo na magistratura, idade, formação em nível de pós-graduação, gênero e local onde exerce a jurisdição.

$$
\text { Quadro } 1
$$

Caracterização dos magistrados entrevistados

\begin{tabular}{|lccc|}
\hline Grau de jurisdição e entrância & $\begin{array}{c}\text { Código } \\
\text { entrevistado }\end{array}$ & $\begin{array}{c}\text { Tempo na } \\
\text { magistratura } \\
\text { (em anos) }\end{array}$ & $\begin{array}{c}\text { Atividade exercida } \\
\text { antes de ingressar na } \\
\text { magistratura }\end{array}$ \\
\hline Primeiro Grau / Entrância Inicial & M3 & Entre 10 e 15 & Advocacia privada \\
Primeiro Grau / Entrância Intermediária & M5 & Entre 10 e 15 & Advocacia privada \\
Primeiro Grau / Entrância Intermediária & M11 & Entre 10 e 15 & Estágio em direito \\
Primeiro Grau / Entrância Intermediária & M12 & Entre 10 e 15 & Assessoria jurídica \\
Primeiro Grau / Entrância Final & M1 & Entre 20 e 25 & Advocacia privada \\
Primeiro Grau / Entrância Final & M2 & Entre 20 e 25 & Advocacia privada \\
Primeiro Grau / Entrância Final & M4 & Entre 10 e 15 & Advocacia pública \\
Primeiro Grau / Entrância Final & M7 & Entre 10 e 15 & Advocacia pública \\
Primeiro Grau / Entrância Final & M8 & Entre 20 e 25 & Advocacia privada \\
Primeiro Grau / Entrância Final & M10 & Entre 20 e 25 & Advocacia privada \\
Segundo Grau & M6 & Mais de 25 & Advocacia privada \\
Segundo Grau & M9 & Mais de 25 & Advocacia pública \\
\hline
\end{tabular}

Fonte: Elaborado pelos autores.

As entrevistas ocorreram nos locais de trabalho e nas residências dos magistrados e foram gravadas com o consentimento dos participantes e posteriormente transcritas para viabilizar a análise dos dados. Para atender a recomendação de Vergara (2009) no tocante à 
realização de uma entrevista, foram realizadas duas entrevistas-piloto com o objetivo de aperfeiçoar o roteiro de entrevistas e a forma de condução do entrevistador.

Para a análise dos dados foi utilizada a análise de conteúdo na perspectiva de Bardin (2004). A unidade de registro selecionada foi o tema, que é frequentemente usada no estudo de motivações de opiniões, atitudes, valores, crenças e tendências, e as respostas dadas em questões abertas são comumente analisadas tendo o tema como base (Bardin, 2004). A categorização ocorrida decorreu de uma grade de análise mista, com categorias definidas a priori, ou seja, predeterminadas, e a posteriori, emergidas das respostas dos entrevistados.

\section{Apresentação e análise dos dados}

As respostas das 12 entrevistas realizadas foram agrupadas em três categorias analíticas: "a liderança esperada no Judiciário gaúcho"; "o reconhecimento de líderes pelos seus pares dentre os magistrados gaúchos" e "dificuldades para o exercício da liderança pelos magistrados", que serão detalhadas nas seções a seguir.

\subsection{A liderança esperada no Judiciário gaúcho}

A primeira categoria possibilita a verificação de importantes aspectos da liderança que se espera que seja exercida no Poder Judiciário do Rio Grande do Sul. O primeiro aspecto é que todos os entrevistados expuseram que a existência de líderes no Judiciário é algo necessário para a definição de objetivos do poder e para qualificar a prestação jurisdicional oferecida à sociedade. Foram identificados dois papéis da liderança no setor público apontadas pela Ocde (2002): que os líderes são agentes de mudança e reforma e responsáveis pela motivação das equipes e pela disponibilização de meios para o alcance da missão organizacional. Há também a convergência com o exposto por Bass (1990) de que a existência de lideranças em uma organização é um fator importante para o seu sucesso.

Entretanto há a compreensão da importância de a existência de líderes pelos magistrados não ficar restrita ao nível estratégico do Judiciário gaúcho, ou seja, o Tribunal de Justiça, pois os entrevistados M5, M7, M11 e M12 expuseram que tal existência também é fundamental nas unidades jurisdicionais.

Dado que o magistrado é o responsável maior pela gestão das unidades jurisdicionais, seja no primeiro ou no segundo graus, mesmo havendo servidores com cargos de chefias com a responsabilidade operacional da administração cartorária, é razoável a expectativa de que o próprio magistrado assuma um papel de liderança junto aos seus subordinados hierárquicos. Desta forma, será possível obter o engajamento da equipe e a superação da mera obediência à autoridade do cargo. A possibilidade de superação da obediência ao poder de mando oriundo do cargo é um dos motivos pelos quais a liderança no setor público despertou interesse dos gestores públicos, conforme a Ocde (2002). 
O segundo aspecto sobre a liderança esperada no Judiciário gaúcho identificado nas falas apresenta as habilidades esperadas dos magistrados líderes: ser inovador e criativo para a superação das dificuldades do ambiente de trabalho; ter grande conhecimento técnico sobre o trabalho a ser realizado; ser capaz de mobilizar sua equipe mediante o conhecimento dos seus membros (através da compreensão dos sentimentos, atitudes e do que os motiva) e de definir objetivos claros a serem alcançados. Neste sentido, foram verificadas algumas das atitudes da liderança, apontadas por Limongi-França e Arellano (2002) e Yukl (2010), como estimular o trabalho em equipe, ter uma visão clara dos objetivos e saber transmiti-la. Também verifica-se a capacidade de relacionar-se com os liderados apontada por Oliveira, Sant'Anna e Vaz (2010).

O terceiro aspecto verificado é que não houve unanimidade entre os respondentes acerca de a liderança ser algo inerente à atividade da magistratura. Três magistrados (M2, M5 e M7) afirmaram que sim em razão da importância do cargo ocupado e do seu reflexo perante a sociedade, conforme é demonstrado na manifestação a seguir:

Eu acho que a atividade do juiz tem sim inerente a atividade da liderança porque ele está atrelado não só a um grupo de trabalho que está no gabinete mas principalmente o grupo de trabalho que está no cartório, e cabe a ele fazer essa integração dos dois grupos, cabe a ele fazer esse pessoal todo compreender que a atividade ali é uma só, que uma providência cumprida por um ou tomada por outro ela vai ter influência no trabalho de outro colega etc. etc. Na comunidade também, especialmente nas comunidades menores, em que a figura do juiz na verdade é a do próprio Judiciário (M7).

Entretanto, outros cinco respondentes (M3, M4, M9, M10, M11) entenderam que o magistrado é o superior hierárquico da unidade em que está lotado, mas que isso não faz com que ele seja considerado um líder, mesmo que represente o Poder Judiciário em sua localidade. A fala abaixo exemplifica tal compreensão:

Eu acho que não, não é não pelo fato de exercer uma função de poder de Estado eu não vejo essa relação. É a mesma questão da diferença de um chefe e da liderança. Uma coisa é ter o poder jurisdicional para definir e outra coisa é exercer uma liderança, uma capacidade de influenciar as outras pessoas, a ponto a ser guindado a essa figura de líder, mas eu não vejo relação, não deveria ter. Claro que há uma confusão em relação a isso, pode haver uma confusão, mas eu entendo que não haja (M10).

Para estes cinco entrevistados, a autoridade do cargo não faz com que seu ocupante seja um líder, confirmando o exposto por Yukl (2010). Neste sentido também afirma Kotter (2000) de que existe diferença entre gerenciamento e liderança, embora as duas atividades sejam complementares.

Apesar de não haver unanimidade em relação à ideia de que a liderança é algo inerente à magistratura, os entrevistados expuseram que existem situações em que é exigido 
que um magistrado exerça um papel de líder. Tais manifestações foram categorizadas em duas situações.

A primeira é perante a sociedade em que está inserido por influenciar comportamentos por meio de manifestações genéricas sobre os conflitos sociais que estão sendo apreciados ou em razão dos esclarecimentos dos direitos aos cidadãos. Especial destaque foi dado à importância da ação dos magistrados na realização de ações que causam impacto direto na comunidade a partir da articulação de ações nas áreas da infância e juventude, carcerária, saúde, educação e segurança pública. Entretanto, o entrevistado M8 alertou que esse papel proativo da magistratura em seu meio social deve ocorrer de modo a preservar sua imparcialidade constitucional no exercício da função judicante.

A segunda situação na qual é exigido que um magistrado exerça um papel de líder é "no âmbito da própria vara, no âmbito interno, em relação aos seus servidores, em relação ao atendimento das pessoas que procuram esse atendimento de serviço" (M2). De modo a conhecer mais essa realidade, os entrevistados foram questionados acerca das maneiras pelas quais um magistrado pode influenciar os seus subordinados. As respostas dadas expuseram que as ações pelas quais os magistrados influenciam seus subordinados hierárquicos são: definir metas e indicadores para sua mensuração; conhecer e valorizar os servidores; criar um espírito de equipe; compartilhar os resultados positivos obtidos; motivar de modo a comprometer a equipe para o alcance dos objetivos; e dar o exemplo ao participar ativamente na solução dos problemas. Foram identificadas algumas das características dos líderes expressas por Limongi-França e Arellano (2002) e Yukl (2010), tais como conhecer a realidade em que atuam os liderados, estimular o trabalho em equipe, criar um comprometimento com o trabalho e viabilizar a realização de atividades complexas.

Portanto, foi possível verificar a partir das respostas analisadas que a existência de lideranças no Judiciário gaúcho é algo necessário não só para definir os objetivos de atuação do poder e para qualificar a prestação jurisdicional oferecida à sociedade, mas também porque do magistrado é exigido que ele seja uma liderança em duas situações: perante a sociedade e perante sua unidade cartorária. Para atender a tais exigências e necessidades, é esperado que o magistrado possua algumas características e habilidades que, conforme será explorado na seção 5.3, não são desenvolvidas durante a formação do bacharel em direito e nem são requisitos para o ingresso na magistratura.

\subsection{O Reconhecimento de líderes pelos seus pares dentre os magistrados gaúchos}

A segunda categoria de análise identifica o que propicia o reconhecimento de lideranças dentre os magistrados do Rio Grande do Sul por seus pares. Todos os entrevistados reconheceram a existência de colegas magistrados como lideranças dentro do Judiciário gaúcho. Ao serem questionados sobre o que faz com que tais magistrados sejam considerados lideranças dentro da instituição, os respondentes elencaram os seguintes aspectos: eleição e escolha para ocupar 
cargos importantes; conhecimento jurídico; capacidade de gestão; e habilidades na mobilização e na interação com os demais magistrados.

Um magistrado pode ser eleito para cargos diretivos na Associação dos Juízes do Rio Grande do Sul (Ajuris), entidade privada que representa os magistrados, e no Tribunal de Justiça. Segundo os entrevistados M4, M8, M9 e M10, a eleição para algum destes cargos faz com que um magistrado seja reconhecido como uma liderança. Retomando o exposto por Yukl (2010), um líder encontra maior possibilidade de aceitação quando é eleito. Para os entrevistados M2, M4 e M12, a escolha de um magistrado ser temporariamente juiz-corregedor, diretor do foro ou diretor ou subdiretor de um dos departamentos da Ajuris é também um indicativo de que ele é uma liderança perante a magistratura.

O segundo aspecto destacado pelos participantes que faz com que um magistrado seja reconhecido como uma liderança é o seu conhecimento jurídico, conforme os entrevistados M6, M7, M8 e M10. Além do preparo técnico sobre temas específicos, outro aspecto destacado foi a aplicação deste conhecimento jurídico em sentenças que inovem na aplicação da lei e que propiciem a solução dos conflitos sociais. Tais magistrados "exercem uma natural liderança na questão jurisdicional e acabam sendo inclusive referência pelos demais” (M1).

O terceiro aspecto apontado que leva ao reconhecimento de um magistrado como uma liderança, conforme os entrevistados M1, M2, M3, M6, M7, M11, M12, é seu conhecimento em gestão e a forma como este conhecimento é aplicado na qualificação da atividade-meio prestada nas unidades jurisdicionais. Neste aspecto foram elencadas três habilidades, sendo a primeira a capacidade de superar problemas. A segunda habilidade exposta foi a "disposição para o diálogo, a humildade de reconhecer que tu não tem a solução para tudo, que tu não trabalha sozinho, que tu precisa de um grupo para produzir" (M3). Neste sentido da importância do trabalho em grupo, foram destacados os magistrados que estimulam o trabalho em equipe dos servidores que trabalham no gabinete e no cartório. A importância do líder para viabilizar o trabalho em equipe condiz com o indicado por Limongi-França e Arellano (2002). A fala a seguir expõe a importância de haver uma integração das atividades desenvolvidas nesses dois órgãos de modo a haver a plena efetividade da decisão proferida:

(...) na atividade do juiz especificamente é muito fácil ficar no gabinete, esperar que os processos cheguem até ele, decidir aquilo que chega, e não se preocupar com o que está acontecendo na sala do lado. Se aquela decisão, se aquela sentença que ele prolatou há 30 dias já chegou no conhecimento, digamos, oficial das partes, para que a partir possa correr o prazo, para que a partir dali possa se interpor recurso, definitivamente se resolveu a situação ou não. Então é muito mais fácil, na maioria das vezes, pensar: não, o meu serviço está em dia, porque eu não tenho nenhum processo aqui para decidir. Mas ao mesmo tempo ignorar que na sala ao lado, no cartório, esse serviço em dia não é em dia, porque a pessoa que está no lado de lá do balcão está esperando que aquela sentença seja efetivada há meses, então a compreensão da importância de toda essa engrenagem como uma coisa só, né, que para o jurisdicionado é traduzido como a prestação da justiça, é essencial para que o juiz comece a não só a se interessar, mas que comece a se inteirar e a intervir nessas atividades todas que acontecem no cartório (M7). 
A inovação no âmbito administrativo foi a última habilidade identificada a partir das falas dos entrevistados. As medidas administrativas mencionadas consideradas inovadoras foram no sentido de padronizar procedimentos para processos de determinados temas que visam à diminuição do período de tramitação do processo em cartório.

A capacidade de apreciar processos de modo a atender à demanda é outra qualidade que faz com que haja o reconhecimento de um magistrado perante seus pares, conforme o entrevistado M8: "Na magistratura o juiz trabalhador ele é reconhecido pelos outros, pelos demais. Na nossa instituição, trabalhar bastante é um valor. Pela qualidade e quantidade. Nos dois aspectos. Se ele une qualidade e quantidade, bom, aí ele passa a ser um paradigma".

Tal situação é condizente com o esperado com um ambiente burocrático, dado que uma das características deste tipo de organização é que o burocrata é um especialista para exercer determinada função e segue uma carreira na qual há uma progressão em razão do tempo de serviço e/ou eficiência (Motta e Bresser-Pereira, 2004). A avaliação dos magistrados para fins de progressão na carreira é baseada tanto em critérios quantitativos quanto qualitativos.

O quarto aspecto mencionado que identifica um juiz como uma liderança foi a capacidade de mobilizar e interagir com os demais magistrados. Como exemplificado pelo entrevistado abaixo, de que um magistrado

(...) precisa ter interação com os colegas, precisa saber reconhecer os demais, não ser aquele sujeito que seja muito vedete, que puxe para si, que fique jogando confete em si mesmo, é um sujeito que saiba reconhecer que o resultado foi trabalho também de outras pessoas. Ele também precisa ser um cara que saiba delegar e atribuir responsabilidades, fazendo um empoderamento, convencendo os seus pares de que eles precisam tomar parte nessa, naquela empreitada, porque aquilo vai ser importante para a melhoria da instituição, então atribui responsabilidades e depois reconhecer o trabalho de todos (M4).

Foi destacado que a interação entre magistrados deve ser pautada pela predisposição de muito diálogo, de modo a minimizar as resistências às propostas de mudanças:

Eu não falei uma coisa bastante importante. Tem que ter um cuidado com a liderança, mesmo as lideranças propositivas, em razão das proposições que faz, podem ser mal-interpretadas: "mas bah, o que está querendo mudar, o que esse cara está pensando da vida, isso aí é uma idiotice etc. etc. etc.", então elas causam muita reação, então às vezes na magistratura é melhor uma liderança... como é que eu diria, indutiva e não tão propositiva. É melhor uma liderança que não tenha resistências, que implante pequenas modificações, e que nessas pequenas modificações converse exaustivamente com todo mundo, certo, ou seja, é mais importante na magistratura, é muito mais importante na magistratura não ter resistências do que ter iniciativa (M6).

A partir das manifestações dos entrevistados é possível constatar que um magistrado é reconhecido como tal pelos seus pares se ele tiver alguns dos atributos esperados do líder público brasileiro contemporâneo, expostos por Oliveira, Sant'Anna e Vaz (2010), como ca- 
pacidade de comunicação; capacidade de lidar com os liderados; legitimidade; bom senso; e capacidade de agregação. Também é verificada correspondência entre as características da liderança esperada no Judiciário apontadas na seção 5.1 com as características demonstradas pelos magistrados que são reconhecidos como lideranças pelos seus pares: ter capacidade de comunicação e de trabalhar em grupo, ter conhecimento sobre a atividade a ser realizada e ser inovador no que tange aos aspectos de gestão.

\subsection{Dificuldades para o exercício da liderança pelos magistrados}

A última categoria de análise possibilita a identificação das dificuldades para o exercício da liderança pelos magistrados perante os seus pares e subordinados. Tais dificuldades foram classificadas em três grupos temáticos: estruturais; de diálogo e cooperação entre magistrados; e da falta de formação específica em liderança e gestão.

\subsubsection{Dificuldades estruturais}

Há cinco dificuldades identificadas como estruturais do Judiciário. A primeira é a restrição orçamentária para a viabilização de ações que ampliem o efeito da liderança, o que faz com que os magistrados procurem soluções de baixo custo ou custo zero para que alguma atividade inovadora no âmbito administrativo ou perante a sociedade ocorra. A segunda é a falta de estrutura material. A terceira é a elevada carga de trabalho. A quarta e a quinta dificuldades estruturais apontadas foram a impossibilidade de escolha dos colegas de trabalhos e a dificuldade de motivar os servidores públicos em razão da estabilidade.

Neste sentido, foi verificada uma das dificuldades de liderança no setor público brasileiro apontada por Oliveira, Sant'Anna e Vaz (2010) no tocante à impossibilidade de adoção de mecanismos de motivação dos liderados em razão dos planos de carreiras e das regras predefinidas de remuneração. As dificuldades de ordem estrutural são situações que praticamente estão fora da ingerência de um ou de poucos líderes, pois decorrem de situações que são determinadas por lei, pela ampliação da judicialização de litígios e pela limitação dos recursos públicos. A minimização de algumas destas dificuldades, especialmente no tocante a recursos materiais e financeiros, exigiria uma articulação política junto aos demais poderes.

\subsubsection{Dificuldades de diálogo e cooperação entre magistrados}

A análise das manifestações dos entrevistados viabilizou a identificação de dificuldades no que tange ao diálogo e à cooperação entre magistrados. Um entrevistado observou que há dificuldades no exercício da liderança entre magistrados em razão de uma dificuldade de estabelecimento de um diálogo entre indivíduos que são autoridades no meio social em que atuam: 
A liderança entre juízes não é fácil. Na verdade, todo juiz ele assume uma enorme responsabilidade que é correspondida com poder. Este exercício do poder continuado faz do juiz alguém que se sente diferenciado e uma liderança natural. Quanto tu reúne muitas pessoas que são líderes nas suas localidades, tu tem algumas dificuldades em se sobressair, em relação, ou pelo menos, às vezes, mostrar que há outros caminhos. Então em uma reunião de juízes normalmente a gente discute muito, porque todos estão acostumados a dar a última palavra. E é um exercício muito interessante esse, por isso que eu procuro sempre participar da associação, porque para mim é um aprendizado essas reuniões de conselhos, onde cada um dá a sua opinião que não necessariamente é decisão. Alguns não conseguem compreender que quando estamos em um processo de discussão, aquilo que ele diz não é a palavra final, é a opinião dele, e a partir dali nós podemos construir uma decisão conjunta, por maioria ou por consenso. Quem está acostumado a dar a palavra final às vezes tem alguma dificuldade disso, eu acho que essa pode ser uma dificuldade (M8).

Outro aspecto abordado foi a inibição para a divulgação de iniciativas de liderança. Um dos entrevistados expôs que "muitos colegas desenvolvem boas práticas e se sentem até constrangidos de multiplicar aquilo, o que eu acho um erro, se sentem... daqui a pouco vão ser objeto de críticas de outros colegas" (M5). Tal afirmação reafirma o exposto anteriormente de que há uma grande resistência por parte de setores da magistratura para que algumas práticas sejam modificadas. Heifetz e Laurie (1997 apud Schwella, 2005) expõem que o apoio às pessoas que manifestam opiniões, críticas e sugestões é um dos princípios para o exercício da liderança no setor público.

As críticas sofridas podem, no entender de dois entrevistados, ser motivadas pela inveja da projeção decorrente do reconhecimento:

A magistratura é uma carreira, e como carreira ela traz dois tipos de sentimentos, duas formas de se atuar: há magistrados que quando veem um bom trabalho rapidamente tentam pegar aquela formatação, pegar aquele trabalho exatamente para auxiliar o seu trabalho, no sentido de olha, que bacana, uma coisa nova, uma coisa que pode funcionar, que pode nos auxiliar, vamos adotar, e há magistrados que agem exatamente no sentido inverso, eles tentam destruir o que foi apresentado, desconstruir de regra, desconstruindo e atacando a pessoa, o autor da ideia, exatamente porque é uma carreira, e eles vislumbram ali que é um concorrente que está se sobressaindo. Então esse é um problema (M6).

E dá muita ciumeira, também, porque tu começa, o pessoal gosta da tua liderança, e o pessoal fica meio melindrado porque os servidores começam a gostar de ti, mais de ti, e querem que tu fique, tem essas coisas (M11).

Tendo em vista que a magistratura é uma carreira e um dos critérios de avaliação é o merecimento, sendo este mensurado pelas iniciativas tanto na parte jurisdicional quanto na parte administrativa, é compreensível (mas não desejável para a qualificação dos serviços prestados à sociedade) que tais situações ocorram. 
Outra dificuldade exposta foi a falta de colaboração entre magistrados, em razão do não interesse em participar da solução de problemas de ordem administrativa:

Magistrados assim ó, nunca nenhum chegou e me disse assim:, "eu não quero aderir, eu não acredito". Nunca disseram, mas no fundo era isso. Porque era assim: "então tá, tu faz o que tu queres", tipo... tu vias um descrédito, não impediam mas tu via que nitidamente não acreditavam. (...) Então muitos colegas não querem porque a gente já tem muito trabalho, realmente, a gente tem pilhas e pilhas, milhares de processos e ainda tu tem que dedicar tempo para isso, reuniões mensais como eu fazia com a minha vara, depois na direção eu fazia com esse povo todo, eu fazia com os escrivães, com os oficiais de justiça, eu fazia com os da segurança, porque dava problema de segurança com os guardinhas lá embaixo, com o pessoal da limpeza, era assim porque tu tinha que, até para tu teres um quadro de todo o fórum, de todos os problemas, de todas as reivindicações, para tentar que o pessoal mais tranquilo, o pessoal se motivar, é trabalheira. $\mathrm{E}$ se os juízes ajudassem os outros ia ser muito mais fácil. Inclusive tinha reuniões entre os juízes, aí não vão, não aparecem, então é assim, não negam mas também não ajudam em nada e não estão nem aí. E seria muito bom se ajudassem. Porque é cansativo, desgasta (M11).

Sem diálogo entre os magistrados é inviável a superação da resistência a mudanças em razão do apego por práticas já consolidadas: "a maior dificuldade geralmente é o medo da mudança. De regra a grande resistência por parte dos servidores e por parte dos próprios colegas é o medo da mudança. Se as coisas são feitas assim há 50 anos, assim deve continuar" (M6). Em uma organização burocrática, a resistência a mudanças é algo esperado tendo em vista ser ela uma organização alicerçada na previsibilidade dos comportamentos de seus membros; entretanto, o apego excessivo às regras e aos procedimentos consolidados inviabiliza a melhoria dos processos internos e dos resultados alcançados.

Tendo em vista a autonomia para o exercício das suas atribuições definidas constitucionalmente e pela legislação em vigor, fica clara a necessidade de engajamento dos magistrados na qualificação da prestação jurisdicional dada à sociedade, e tal atitude deve decorrer do interesse em efetivamente colaborar para que haja uma cooperação, mínima que seja, entre os juízes.

\subsubsection{Dificuldades decorrentes da falta de formação do magistrado em liderança e gestão}

À exceção do entrevistado M10, os demais 11 magistrados responderam que identificam a necessidade de uma formação em liderança para a magistratura gaúcha. A necessidade de formação em liderança foi relacionada com outros conhecimentos que os entrevistados entenderam ser importantes para a qualificação do exercício da função jurisdicional. Um conhecimento que foi mencionado por cinco dos entrevistados (M2, M3, M12, M11 e M7) é a necessidade de aprimoramento em conhecimentos na área de gestão, como é exemplificada 
pela fala de um dos entrevistados: "O juiz não é preparado para administrar. Não é preparado para trabalhar esses outros aspectos que não os aspectos jurídicos. Nós não somos exigidos em relação a isso nos concursos e a nossa preparação não é voltada para isso" (M3). A carência de conhecimentos em gestão é destacada na dificuldade em planejar:

Essa tradição e esse conservadorismo da justiça por um lado é importante porque dá uma certa estabilidade para a instituição, mas, por outro lado, essa nossa estrutura de pensamento de sempre no processo eu acho que, para facilitar um pouco o que estou dizendo, o juiz atua em duas perspectivas. Ele atua na atividade meio e na atividade fim. Na atividade fim que é a jurisdição, ele sempre faz isso de forma retrospectiva, um juiz quando ele examina um caso ele olha para trás, e ele sempre busca apurar como os fatos se passaram a partir das versões das partes, das provas apresentadas, criando sempre retrospectivamente. Isso faz com que ele tenha quase um vício de analisar as coisas sob essa perspectiva do passado, olhando sempre para o passado e tentando encontrar soluções do futuro. Na administração é um pouco diferente disso, tu tem que imaginar um cenário logo adiante, antever esse cenário para então poder planejar e achar as soluções, e nós temos uma dificuldade cultural de fazer esse tipo de pensamento prospectivo. $\mathrm{O}$ nosso pensamento é educado para ser retrospectivo (M8).

Tal dificuldade dos magistrados em planejar as ações do Judiciário condiz com o exposto por Nalini (2006) e Vieira (2009).

Também foi apontada pelos entrevistados M2, M8, M11 e M12 a necessidade de obtenção de conhecimentos em gestão de pessoas, especialmente na parte de motivação dos subordinados. Um dos entrevistados afirmou que tais conhecimentos deveriam ser cobrados inclusive na etapa de seleção dos magistrados:

Por exemplo, quantos concursos que existem aí que exigem do candidato conhecimento de várias ciências, de várias disciplinas, então o sujeito para fazer concurso para auditor fiscal da receita ele tem que ter noções de direito, ter noções de matemática financeira, tem que ter noções de economia; por que para fazer concurso para juiz a pessoa precisa ser habilitada e qualificada só nas ciências jurídicas? Eu acho que isso passa também pela exigência de uma qualificação profissional lá no início, olha: ó, quer ser candidato a juiz, bom, precisa ser formado em direito, com bom, com ótimo conhecimento das ciências jurídicas, mas tu precisa ter também noções de administração, pois a atividade que tu vai desenvolver não é só pegar processo e julgar se o pedido precisa ser acolhido ou não, de estabelecer aquele silogismo lá da lei, do fato, valor e norma etc. etc., tu vai precisar ter uma compreensão para poder organizar a unidade onde tu vai trabalhar e conduzir esse grupo aí aos resultados (M7).

Kotter (2000) expôs a relação de complementaridade entre gerenciamento e liderança, portanto não é surpreendente que haja a menção destes conhecimentos relacionados à administração quando os entrevistados foram questionados sobre liderança. 
Quando questionados sobre o momento da carreira em que tal formação deveria ocorrer, sete entrevistados (M4, M5, M7, M8, M9, M11 e M12) entendem que tal capacitação deve ocorrer desde o início da carreira do magistrado. Oliveira, Sant'Anna e Vaz (2010) expõem que é possível a existência de atividades de desenvolvimento de liderança no setor público, desde que haja uma conciliação entre a obtenção de conhecimento teórico com sua aplicação em situações práticas na realidade do aluno. Também neste sentido Bacon (1999) confirma a possibilidade de desenvolvimento de líderes na área pública.

No que tange à formação de lideranças no setor público, reforça-se o cuidado apontado pela Ocde de que não existe um modelo universal e ideal de liderança do setor público em razão da diversidade entre realidades distintas. Portanto, para que haja o desenvolvimento de lideranças dentre os magistrados, são necessárias atividades que contemplem as peculiaridades da atividade do juiz e as características dos participantes de uma ação desta natureza.

\section{Conclusões}

Neste estudo, que teve como objetivo identificar o que faz com que um magistrado da Justiça Estadual do Rio Grande do Sul seja reconhecido como um líder pelos seus pares, identificaram-se as características da liderança esperadas e existentes na magistratura, os aspectos que fazem com que os magistrados sejam reconhecidos como líderes e as dificuldades existentes para o exercício da liderança nesta instituição pública. Deste modo, há uma ampliação do campo de estudo sobre o Judiciário na área de comportamento organizacional mediante um tema pouco explorado em estudos nacionais no setor público.

A análise das entrevistas possibilitou verificar que a existência de magistrados líderes é necessária para qualificar a prestação jurisdicional oferecida à sociedade e para a definição de objetivos de atuação do Judiciário gaúcho. É esperado que tal liderança ocorra em todos os níveis organizacionais (do Tribunal de Justiça até as unidades jurisdicionais), de modo a atender as expectativas da sociedade e dos servidores. Como conhecimentos e habilidades esperadas do líder na Justiça estão a inovação e criatividade; a visão sistêmica e o conhecimento acerca do trabalho a ser realizado; e as capacidades de mobilização do grupo de trabalho e de definição de objetivos.

A liderança na Justiça não decorre do cargo ocupado, mas sim da iniciativa do próprio magistrado. Para que obtenha o reconhecimento de seus pares, ele deve ser eleito ou escolhido para um cargo, ter profundo conhecimento jurídico demonstrado em sentenças inovadoras e socialmente relevantes, evidenciar capacidade de gestão ou habilidades de mobilização e interação com os demais magistrados, e preparar-se e desenvolver-se continuamente. Estes não são uma exigência da formação do magistrado, cujo foco é a capacidade de interpretação da lei e sua aplicação nos termos do contido em cada processo, atividade por natureza solitária e restrita ao seu gabinete. Parte da literatura em comportamento organizacional oferece suporte para a possibilidade de formação de lideranças, porém ressalta-se que esta precisa ser 
proposta considerando as peculiaridades da atividade de julgar e do setor público, em especial, do Poder Judiciário.

O exercício da liderança entre magistrados gaúchos precisa superar dificuldades estruturais e dificuldades de diálogo e cooperação entre os magistrados em razão da falta de interesse em trabalhar em conjunto com os seus pares na solução de problemas administrativos. O estudo sugere que as de cooperação podem ser minimizadas pelo interesse institucional na formação de lideranças.

A pesquisa também apresenta como limitação a impossibilidade de contato com um número maior de magistrados da entrância inicial (de início de carreira) e com um número maior de desembargadores. A ampliação do número de entrevistados que estão há pouco e há mais tempo na carreira poderia viabilizar a identificação de outros aspectos importantes sobre o reconhecimento de magistrados enquanto lideranças ou a confirmação das análises realizadas.

Para futuras pesquisas recomenda-se a integração entre abordagem qualitativa com a quantitativa (o que possibilitaria a participação maior do número de magistrados e também uma análise mais ampla); a investigação da liderança exercida pelos magistrados ocupantes em cargos eletivos; e o estudo da liderança exercida pelos magistrados pela ótica dos servidores do Judiciário.

\section{Referências}

AKUTSU, Luiz; GUIMARÃES, Tomás A. Dimensões da governança judicial e sua aplicação ao sistema judicial brasileiro. Direito GV, v. 8, n. 1, p. 183-202, 2012.

AMARAL, Helena K. Desenvolvimento de competências de servidores na administração pública brasileira. Revista do Serviço Público, v. 57, n. 4, p. 549-563, 2006.

BACON, Kevin. Além da capacitação: desenvolvimento de líderes para o setor público. Revista do Serviço Público, v. 50, n. 4, p. 83-92, 1999.

BARDIN, Laurence. Análise de conteúdo. 3. ed. Lisboa: Edições 70, 2004.

BASS, Bernard M. Bass \& Stogdill's handbook of leadership: theory, research, and managerial applications. 3. ed. Nova York: The Free Press, 1990.

BERGAMINI, Cecília W. Liderança: administração do sentido. 2. ed. São Paulo: Atlas, 2009.

BRASIL. Constituição. 1988. Disponível em: <www.planalto.gov.br/ccivil_03/Constituicao/Constituicao.htm>. Acesso em: 23 fev. 2013.

CONSELHO NACIONAL DE JUSTIÇA. Justiça em números 2011 - Justiça estadual. Brasília: Conselho Nacional de Justiça, 2012. Disponível em: <www.cnj.jus.br/images/pesquisas-judiciarias/Publicacoes/rel_completo_estadual.pdf>. Acesso em: 26 fev. 2013. 
COSTA, Silvia G.; MARTINESWKI, Cláudio L.; VIEIRA, Luciano J. M. Planejando a estrutura do Judiciário para o futuro: a difícil busca por indicadores confiáveis. Revista da Ajuris/Associação dos Juízes do Rio Grande do Sul, v. 33, n. 103. p. 305-322, 2006.

DAVEL, Eduardo; MACHADO, Hilka V. A dinâmica entre liderança e identificação: sobre a influência consentida nas organizações contemporâneas. Revista de Administração Contemporânea, v. 5, n. 3, p. 107-126, 2001.

GODOY, Arilda S. Refletindo sobre critérios de qualidade da pesquisa qualitativa. Gestão.org — Revista Eletrônica de Gestão Empresarial. v. 3, n. 2, p. 86-94, 2005.

JOBIM, Nelson. Judiciário: construindo um novo modelo. In: FUNDAÇÃO GETULIO VARGAS. A reforma do Poder Judiciário no estado do Rio de Janeiro. Rio de Janeiro: Fundação Getulio Vargas, 2005. p. 13-16.

KOTTER, John P. Afinal, o que fazem os líderes? A nova face do poder e da estratégia. 2. ed. Rio de Janeiro: Campus, 2000.

LIMONGI-FRANÇA, Ana C.; ARELLANO, Eliete N. Liderança, poder e o comportamento organizacional. IN: FLEURY, Maria Tereza Leme. As pessoas na organização. 11. ed. São Paulo: Gente, 2002. p. 259-270.

MARTINS, Bibiana V. et al. Avaliação de desempenho individual no setor público brasileiro: análise da produção acadêmica de 2000 a 2009. In: ENCONTRO DE ADMINISTRAÇÃO PÚBLICA E GOVERNANÇA, IV, 2010, Vitória.

MERRIAM, Sharan B. Qualitative research and case study applications in education: resived and expanded from case study research in education. São Francisco: Jossey-Bass, 1998.

MOTTA, Fernando C. P.; BRESSER-PEREIRA, Luiz Carlos. Introdução à organização burocrática. 2. ed. São Paulo: Pioneira Thomson Learning, 2004.

NALINI, Renato. A rebelião da toga. Campinas: Millennium, 2006.

NOGUEIRA, José M. M. et al. Estudos exploratórios da eficiência dos Tribunais de Justiça estaduais brasileiros usando a análise envoltória de dados (DEA). Revista de Administração Pública, Rio de Janeiro, v. 46, n. 5, p. 1317-1340, 2012.

OCDE. Organização para a Cooperação e o Desenvolvimento Econômico. Liderança e setor público no século 21. Brasília: Ministério do Planejamento, Orçamento e Gestão, 2002.

OLIVEIRA, Fátima B.; SANT'ANNA, Anderson S.; VAZ, Samir L. Liderança no contexto da nova administração pública: uma análise sob a perspectiva de gestores públicos de Minas Gerais e Rio de Janeiro. Revista de Administração Pública, Rio de Janeiro, v. 44, n. 6, p. 1453-1475, 2010.

PARRY, Ken; BRYMAN, Alan. Leadership in organizations. In: CLEGG, Stewart R. et al. (Ed.). The Sage handbook of organization studies. 2. ed. Londres: Sage, 2006.

SADEK, Maria Tereza A. Poder Judiciário: perspectivas de reforma. Opinião Pública, Campinas, v. 10, n. 1, p. 1-62, 2004. 
SCHWELLA, Erwin. Inovação no governo e no setor público: desafios e implicações para a liderança. Revista do Serviço Público, v. 56, n. 3, p. 259-276, 2005.

TRIBUNAL DE JUSTIÇA DO ESTADO DO RIO GRANDE DO SUL. Planejamento estratégico TJRS. 2010. Disponível em: <www1.tjrs.jus.br/site/poder_judiciario/planejamento_estrategico/>. Acesso em: 28 fev. 2013.

VERGARA, Sylvia C. Métodos de coleta de dados no campo. São Paulo: Atlas, 2009.

VIEIRA, José Luiz L. Um novo desafio para o Judiciário: o juiz líder. Porto Alegre: Tribunal de Justiça do Estado do Rio Grande do Sul, 2009.

VIEIRA, Luciano J. M.; PINHEIRO, Ivan A. Contribuições do Conselho Nacional de Justiça para a gestão do Poder Judiciário. In: ENCONTRO DA ASSOCIAÇÃO NACIONAL DE PÓS-GRADUAÇÃO E PESQUISA EM ADMINISTRAÇÃO, XXXII, 2008, Rio de Janeiro.

VILLORIA, Manuel; IGLESIAS, Ángel. Leadership in public management: some theoretical and methodological considerations. Innovar, v. 21, n. 42, p. 175-189, 2011.

WART, Montgomery V. Public-sector leadership theory: an assessment. Public Administration Review, v. 63, n. 2, p. 214-228, 2003.

YUKL, Gary. Leadership in organizations. 7. ed. Nova Jersey: Pearson, 2010.

Luciano José Martins Vieira é mestre em administração e tutor no curso de Especialização em Gestão Pública da Escola de Administração da Universidade Federal do Rio Grande do Sul (UFRGS). E-mail: ljmvieira@yahoo.com.br.

Silvia Generali da Costa é doutora em administração e professora associada da Escola de Administração da Universidade Federal do Rio Grande do Sul (UFRGS). E-mail: sgeneralicosta@gmail.com. 